\title{
Theoretical and Experimental Study of Mine Surveyors Testing
}

\author{
Victor V. Zverevich'1, Valery M. Tsaplev², Gregory P. Zhukov³, Anna L. Ivanova ${ }^{4}$ \\ ${ }^{1}$ Department of Engineer Geodesy, Petersburg State Transport University, Saint-Petersburg, Russia \\ ${ }^{2}$ Department of Electroacoustics and Ultrasonic Engineering, Saint-Petersburg State Electrotechnical University (LETI), \\ Saint-Petersburg, Russia \\ ${ }^{3}$ Department of Mine Surveying, National Mineral Resources University (Gorny), Saint-Petersburg, Russia \\ ${ }^{4}$ Department of Secondary Education (University School), Saint-Petersburg State University, Saint-Petersburg, Russia \\ Email: valery@convergences-fr.ru, geo@pgups.ru,Zhukov_gp@spmi.ru, a.l.ivanova@spbu.ru
}

How to cite this paper: Zverevich, V.V., Tsaplev, V.M., Zhukov, G.P. and Ivanova, A.L. (2016) Theoretical and Experimental Study of Mine Surveyors Testing. Open Access Library Journal, 3: e3020.

http://dx.doi.org/10.4236/oalib.1103020

Received: September 12, 2016

Accepted: October 7, 2016

Published: October 11, 2016

Copyright $\odot 2016$ by authors and Open Access Library Inc.

This work is licensed under the Creative Commons Attribution International

License (CC BY 4.0).

http://creativecommons.org/licenses/by/4.0/

\section{Abstract}

The working time of a single mine surveyor or the working time of a whole "Mine Surveying Ergatic System" (MSES) depends on various factors. These factors are: different qualities of a surveyor as a professional and a person, his emotion and attention, accuracy and comfort of mine surveying instruments, and the mine working environment. These factors make it possible to conclude the MSES working time to be a stochastic quality. In our research, a unimodal alpha-distribution was used. We have studied the working time of 1 type of MSES: "measurements of horizontal angle". More than 80 mine surveyors and students have taken part in the experiments. The alpha-graphic line shows an accurate interpretation of different points, so it may be used in testing mine surveyors' professional skills.

\section{Subject Areas}

Environmental Sciences

\section{Keywords}

Mine Surveying, Mine Surveying Ergonomic System (MSES), Emotion, Attention, Work Productivity, Random Variable, Working Time Distribution, Normal Law, Working Time, Mathematical Model, Histograms, Alpha-Distribution, Characterizing Points of This Distribution, Testing

\section{Introduction}

Men differ from each other in physiological and psychological qualities. It means that 
they differ in their individuality [1]-[3]. Mine surveying is fulfilled by a group of people, including a mine surveyor (a specialist) and one or two mine workers. The mine surveying team works in a certain mining environment. Hence one can see a functioning system: human being (a mine surveyor)—equipment (a surveying instrument) - mining environment. Such system is called a mine surveying ergatic system (MSES) [4]-[6]. So a mine surveyor is the MSES centre. Nowadays the MSES productivity improvement is possible by taking into consideration the human factor [7] [8]. It means that it is necessary to research the MSES centre (the mine surveyor because he is responsible for MSES productivity) [9]. While analyzing the mine surveying human factor, one can see that productivity and quality of a mine surveyor labour depend on the mine surveyor himself, on his professionalism, on his knowledge and skill, on his psychophysiological state.

High labour productivity is impossible without great emotional tension. Emotion is a psychical process, which reflects human relation to outer irritants or to his own being. Emotion force strengthens the organism or depresses it. Emotions may be positive or negative. Positive emotions appear when the information $I_{r}$ (Information real), which a human being has, is more than prognostical $I_{p r}$ one (Information prognostical), i.e. when $I_{r}>I_{p r}$; negative emotions arise in an opposite case, i.e. when $I_{r}<I_{p r}$ [1]-[3] [10].

The difference of values $I_{r}$ and $I_{p r}$ defines emotional tension, which shows the strength of mobilization (concentration, stamina, etc.) of the worker functions to fulfill various tasks [2] [8] [11]. Any human activity has optimal emotional tension when the human actions are the most effective. Decreasing of emotions slackens working activity. Great emotional tension disorganizes the whole work and the optimal way of achieving the target [1] [2].

Attention is of great importance for a successful activity. Attention is elective mental readiness to define reactions to strictly designated signals. Attention becomes more concentrated if the "where, when and what" information signal appears and when the reaction to this signal is expected. The ideal human working state is the state of attention with certain emotional tension [3] [4] [11] [12].

The goal of this article is to show that the mine surveying work time is a random value and how to use it to appreciate a surveyor's experience.

\section{Theory}

Work productivity of a concrete mine surveyor in definite environment is different and may change during the working time [3] [8] [11] [12]. During the surveying of mines and outputs a mine surveyor must get and estimate the information about the objects having been surveyed or geological and mine conditions. He has to take a true and appropriate decision in order to formulate proper knowledge about the mine enterprise. This working aspect of mine surveying has a very important meaning. Many mine surveyors mark this aspect as a serious improving factor of work tension. It was found as a result of pilot questionnaire among mine surveyors in Vorkuta at a coal company "Vorkutaugol" [5]-[8].

However, while considering surveyor work productivity, we may not get all values of work productivity, because there must be the minimum $\left(a_{\min }\right)$ and maximum $\left(a_{\max }\right)$ 
productivity of the surveyor or of the whole MSES. The first one defines the weakest skill in the profession. The second one corresponds to a high skilled specialist. It means that there is a real productivity condition, expressed by an inequality [1] [13]:

$$
a_{\min } \leq a \leq a_{\max }
$$

in which a-current value of productivity.

This fact suggests that in practice it is necessary to use the truncated normal distribution of MSES survey or work productivity. This curve may be expressed by the formula [13] [14]:

$$
f(t)=\frac{K \beta}{t^{2} \sqrt{2 \pi}} \exp \left[-\frac{1}{2}\left(\frac{\beta}{t}-\alpha\right)^{2}\right]
$$

where $\beta=V / m_{a}$ is relative volume of mine-surveyor's work, $\alpha=a_{a v} / m_{a}$ is a coefficient of mine-surveyor's work homogeneity, $V$-volume of mine-surveyor's work, $m_{a}$-labour productivity of a mine-surveyor, $a_{a v}$-average labour productivity.

The value (бета) is given in time units; the coefficient (alpha) has no units. It is shown in [13], which for practical use of the alpha-distribution one is not obliged to know the work volume $V$ and characteristics $m_{a}$ and $a_{a r}$ But it is sufficient to determine all them statistically.

The Equation (2), named alpha-distribution in [13], is obtained, taking into account of the formula from [6]:

$$
f(a)=\frac{K}{m_{a} \sqrt{2 \pi}} \exp \left[\frac{\left(a-a_{c p}\right)^{2}}{2 m_{a}^{2}}\right]
$$

in which $a_{c p}$-mean value of productivity; $m_{a}$-mean square declination of labor productivity; $K$-normalizing factor that takes into consideration account features of the distribution.

The factor $K$ may be determined from the condition that the area between the $\mathrm{x}$-axis and the curve, given by Equation (3), is equal to unity (see Formula (4)).

$$
K=\frac{1}{\int_{a_{\min }}^{a_{\max }} f(a) \mathrm{d} a}
$$

The value of productivity $a_{\text {mean }}$ and standard deviation $m_{a}$ of mine surveying work productivity may be found experimentally by timing various MSES.

In our MSES functioning research we use the following formulas for calculation $(\alpha)$ and $(\beta)$ from [15]:

$$
\left.\begin{array}{c}
\alpha=\frac{\sum_{i=1}^{n} t_{i}^{-1}}{\sqrt{n \sum_{i=1}^{n} t_{i}^{-2}-\left(\sum_{i=1}^{n} t_{i}^{-1}\right)^{2}}} ; \\
\beta=\frac{n}{\sqrt{n \sum_{i=1}^{n} t_{i}^{-2}-\left(\sum_{i=1}^{n} t_{i}^{-1}\right)^{2}}},
\end{array}\right\}
$$


where $t_{i}$-amine surveyor working time, $n$-excerption volume.

The coefficient $K$, as it is shown in [3] [15], is practically equal to 1 , if $\alpha \geq 2$. But when $\alpha<2$, the following Formula (9) has to be used:

$$
K=\frac{1}{F\left(U_{2}\right)-F\left(U_{1}\right)}
$$

where $\quad U_{1}=\frac{\beta}{t_{k}-\alpha} ; \quad U_{2}=\frac{\beta}{t_{a}-\alpha}, \quad$ and $\quad F(U)=\frac{1}{\sqrt{2 \pi}} \int_{0}^{U} \exp \left(-\frac{x^{2}}{2}\right) \mathrm{d} x$-norminated Laplas function.

For mine surveying tasks it is characteristic that the amount of a particular type of surveying work is not accidental. But the time $T$ of doing the job depends on the executor, the performance of his work and his personality. It means that mine surveyor work time $T$ is a random variable. So random mine surveyor work time $\mathrm{T}$ describes as experience and skill of a separate surveyor and the functioning of the MSES as a whole. The assessment of the time of surveying allows us to construct probable models of MSES work [14].

While choosing the type of the theoretical distribution of working time it must be considered that there is a small quantity of observations. We also should strive to ensure that the distribution parameters have clear physical meaning and dimension of random variable. For surveying working time curve the asymmetry is expected due to the large differences in performers' individuality and conditions of mining surroundings. It is shown in [1] [3] [6] [11] [13] that for random variables of working time a unimodal distribution with positive asymmetry is typical. In this case the following inequality has to exist:

$$
t_{n} \leq t_{m} \leq t_{m e} \leq m_{t} \leq t_{k} .
$$

in which $t_{n}$-the time of schedule (corresponding to $a_{\max }$ ); $t_{m}$-mode of truncated distribution; $t_{m e}$-median of the truncated distribution; $m_{t}$-mathematical expectation of random working time; $t_{k}$-end work time (corresponding $a_{\max }$ ).

The listed in (5) the characteristics of random variable time performance surveyor satisfy the above requirements. It is not difficult to obtain their estimates by the experimental observations. Therefore, for an approximate description unimodal asymmetric distribution of these characteristics fits better than moments of random variables.

We have assumed for the pilot project of constructing a mathematical model of the MSES functioning the alpha-distribution.

Typical alpha-distributioncurve is given in Figure 1.

Characteristic points of this distribution shown in Figure 1 are the following: $t_{n}$ - the graphic beginning, $t_{m}$-the alpha-distribution mode, $t_{m e}$-the alpha-distribution median, $t_{k}$ - the graphic end.

The computer analysis of alpha-distribution curve for different $\alpha$ and $\beta$ has shown, that $\alpha$ and $\beta$ parameters influence the alpha-distribution shape: when decreasing $\alpha$ and increasing $\beta$ alpha-distribution curve becomes more declivous and more asymmetric. The functions $t_{\mathrm{M}} / \beta$ and $t_{\mathrm{M}} / \theta$ from $\alpha$ are given in Figure 2 [1] [3]. 




Figure 1. Typical alpha-distribution curve.



Figure 2. Functions of relations $t_{\mathrm{M}} / \beta$ and $t_{\mathrm{M}} / \theta$ from $\alpha$.

\section{Experiment}

The parameters $\alpha$ and $\beta$ have been calculated by Formulae (5) for MSES "horizontal angle measurements by one stroke" and for MSES "gyro definitions". It was obtained for MSES: gyro definitions": $\alpha=2.75$ and $\beta=56.185 \mathrm{~min}$. The mode volume has been calculated by the formula $t_{\mathrm{M}}=\beta / 4\left(\sqrt{a^{2}+8}-\alpha\right)$ and the points of alpha-distribution density graphic are calculated by equation (7). This graphic is shown in Figure 3, where $\alpha=2.75 ; \beta=56.18 \mathrm{~min} ; t_{\mathrm{M}}=16.9 \mathrm{~min} ; t_{\mathrm{Me}}=20.4 \mathrm{~min}$.

We have got for MSES "horizontal angle measurements by one stroke" $\alpha=2.13$; $\beta=$ $9.31 \mathrm{~min}, t_{\mathrm{M}}=3.3 \mathrm{~min}$. The points of alpha-distribution have been calculated by Equation (5). This curve is given in Figure 4.

The time of these tasks' fulfillment is better described by the alpha-distribution due to the analyses according to Kolmogorov's and David's criteria. The characteristic 
$f(t), \min ^{-1}$



Figure 3. Alpha-distribution density of MSES "gyrodefinitions".

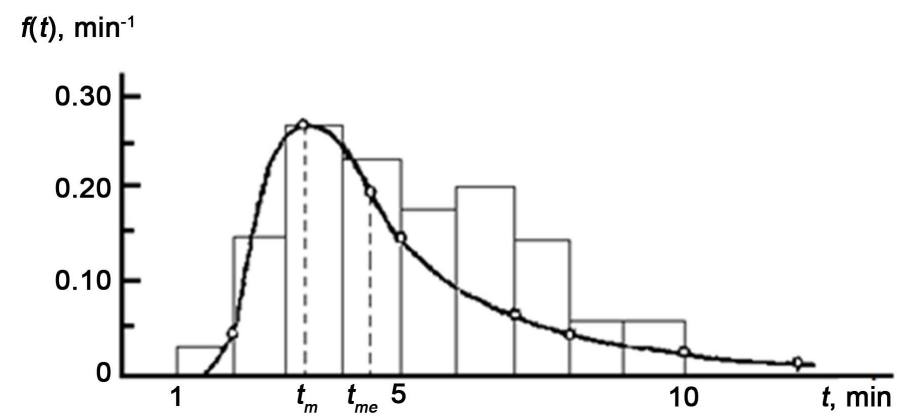

Figure 4. Alpha-distribution density of MSES "horizontal angle measurements by one stroke".

points of the alpha-distribution of MSES working time random value have accurate interpretation: $t_{b}$-the interval beginning or the minimum working time, that is the result of the best mine surveyor in the mining firm. The alpha-distribution mod a $\left(t_{m}\right)$ is the working time of a highly experienced mine surveyor. The value $t_{m e}$ is the alpha-distribution median or the task fulfillment time which is set in fixing of output rates' books. The value $t_{a t}$ is the mathematical expectation of alpha-distribution, i.e. task fulfillment time necessary to certify a mine surveyor. The value $t_{k}$ is the time interval end or the task fulfillment time in professional grading of mine surveying students.

Such characteristics of alpha-distribution curve can be obtained from technical resource books or by time studying of mine surveying tasks. Therefore the time fulfillment of the given MSES characterizes the whole MSES activity. It shows both the professional skills and experience of a mine surveyor and the quality of working in a team. Time index indicates MSES arrangement, shows the MSES productivity and psychophysiological state of workers. According to our experiment the coefficient $\alpha \geq 2$, but not more than 5 , as mine surveying is carried out by versatile staff [13]. The meaning of the coefficient $\alpha>2$ has been proved by the experiment [3] [16]. The alpha-distribution graphic may be used to certify mine surveyors if we choose appropriate task fulfillment time.

\section{Conclusions}

1) Work time of a mine surveyor and his team, i.e. MSES, is a random variable distributed according to the Normal law. 
2) A surveyor's working time may be characterized by truncated unimodal probability alpha-distribution.

3) Mine surveyor's working time schedule is well corresponded by an alpha-distribution, characteristic points of which have clear interpretations.

4) The alpha-distribution suits better for the surveyors' skill interpretation than a triangle one, studied in [17].

5) Experimental constructions of specified schedule for the surveying works "measure of the horizontal angle by one stroke" and "gyrodefinition" have shown that these graphs can be used for hands-on testing and certification of mine surveyors or geodesists.

6) The ideas proposed in the article permit to use chronometric measurements for determinating a surveyor's skill in order to employ a mine-surveyor to fulfill proper and more difficult tasks.

\section{Acknowledgements}

This research was accomplished with the help of the equipment of the Resource Center "Geo-Model" of Saint-Petersburg State University. This work has been accomplished as the part of the Ministry of Education and Science of the Russian Federation research assignment "Realization of scientific research (fundamental studies, applied research and advanced developments)". Project code: 2548.

\section{References}

[1] Babikova, N.N. and Zverevich, V.V. (1998) Probability Model of the Mine Surveying Ergatic System Work Time. Mining Journal, 11-12, 88-91.

[2] Engineering Psychology Principals (1982) Manual for Universities (Reduction by Lomov, B.F.). M.: Mashinostroenye, Moscow, 368 p.

[3] Zverevich, V.V., Korshunov, G.I. and Rybkin, V.K. (1998) The Human Factor in Mine Surveying. Izdatekstvo Nedra, Saint-Petersbury, $184 \mathrm{p}$.

[4] Zverevich, V.V. (1997) Mine Surveyor Ergatic Systems. Formizdat, Saint-Petersburg, 183 p.

[5] Zverevich, V.V., Vakhnin, N.A. and Vakhnina, E.G. (2009) Three Principles and Three Constituents of the Mine Surveying Ergonomics. Economy of Komy Republic, 18, 279-282.

[6] Zverevich, V.V. and Tsaplev, V.M. (2015) A Mathematical Model of Mine Surveying Work Time. American Journal of Environmental Engineering and Science, 2, 60-64.

[7] Zverevich, V.V. and Pandul, I.S. (2011) Fatigability Evaluation of the Mine Surveyor under the Earth. In: Industrial Exploitation of the North Mineral Resources. Problems and Solutions, Proceedings of the 9th International Scientific and Practical Conference, Vol. 2, Vorkuta Mining College, The Branch of the National Mineral Resources University (Gorny), Vorkuta, 360-363.

[8] Zverevich, V.V. (2013) Mine Surveyor Working Place Arrangement. In: Industrial Exploitation of the North Mineral Resources. Problems and Solutions. 11 th International Scientific and Practical Conference, Vorkuta Mining College, The Branch of the National Mineral Resources University (Gorny), Vorkuta, 286-288.

[9] Zverevich, V.V. and Tsaplev, V.M. (2013) The Influence of the Noise on Mine Surveyor. In: Drebenstedt, C. and Singha,l R., Eds., Mine Planning and Equipment Section, Proceedings 
of 22nd MPES Conference, Dresden, 14-19 October 2013, Vol. 1, 659-664.

[10] Zverevich, V.V. and Tsaplev, V.M. (2015) Fractal Method of Evaluation of the Effect of Noise on the Workers in the Mine. Proceedings of the V th International Conference, Protection from the High Noise and Vibration, Saint-Petersburg, March 2015, 694-700.

[11] Zverevich, V.V. and Slyunin, K.Yu. (2009) Innovation in Supporting of Strip-Mining. In: Industrial Exploitation of the North Mineral Resources. Problems and Solutions. Proceedings of the 7 th International Scientific and Practical Conference, Vol. 1, Vorkuta Mining College, The Branch of the National Mineral Resources University (Gorny), Vorkuta, 71-73.

[12] Zverevich, V.V. and Tsaplev, V.M. (2013) Noise and the Work Time of Mine Surveyor under the Earth. Proceedings of the IV th Russian-International Scientific-Practical Conference: Protection from the Noise and Vibration, Saint-Petersburg, 26-28 March 2013, 646 651.

[13] Druzhinin, G.V. (1984) Analysis of Ergotechnical Systems. Energoatomizdat, Moscow, 160 p.

[14] Johnson, N.J. and Leone, F.C. (1977) Statistics and Experimental Design in Engineering and Physical Sciences, Vol. 1. 2nd Edition, John Wiley and Sons, New York.

[15] Krylov, V.N. (1975) Determination of Alpha-Distribution Maximum Probable Values of Systems Running Faultlessly Till Refusal. Proceedings of Moscow Institute of Railway Transport Engineers, Vol. 503, 43-50.

[16] Zverevich, V.V. and Stenin, N.I. (1998) The Modelling of Mine Surveying Works. Izdanelstvo Nedra, Saint-Petersburg, 60 p.

[17] Zverevich, V.V., Novikova, E.I. and Plotnikova, Yu.V. (2004) Ergonomic Evaluation of Mine Surveyor's Tools. Proceedings of the Mining Institute, Vol. 156, 167-170.

Submit or recommend next manuscript to OALib Journal and we will provide best service for you:

- Publication frequency: Monthly

- 9 subject areas of science, technology and medicine

- Fair and rigorous peer-review system

- Fast publication process

- Article promotion in various social networking sites (LinkedIn, Facebook, Twitter, etc.)

- Maximum dissemination of your research work

Submit Your Paper Online: Click Here to Submit

Or Contact service@oalib.com 